\title{
Múltiplos melanomas malignos em área de cicatriz de queimadura: relato de caso e revisão da literatura
}

\section{Multiple malignant melanomas at burn scar: case report and review of the literature}

Victor Hugo Maion'; Elisete Lopes Guilherme²; Carla Maria Ramos Germano3 ; Lucimar Retto da Silva de Avó ${ }^{4}$

\section{unitermos}

Melanomas malignos múltiplos

Cicatriz de queimadura

Lesão hiperpigmentada

\section{resumo}

Alterações neoplásicas malignas podem ocorrer em aproximadamente $2 \%$ dos casos de cicatrizes de queimaduras. As lesões neoplásicas se apresentam mais freqüentemente como carcinoma espinocelular. Neste artigo descreve-se o caso de uma paciente do sexo feminino, na sexta década de vida, com melanomas malignos múltiplos que se desenvolveram em uma antiga área de cicatriz de queimadura no tronco. Melanomas malignos múltiplos que se desenvolvem em região de cicatriz de queimadura são extremamente raros, e apenas quatro casos foram descritos na literatura até o presente momento.

\section{abstract}

Malignant changes in burn scars can develop in approximately $2 \%$ of patients. The majority of these lesions are squamous cell carcinomas. In this article we present the case of a female patient, in the sixth decade, with multiple melanomas arising in the setting of an extensive old truncal burn scar. Multiple malignant melanomas arising in a burn scar are extremely uncommon and only four previous cases have been described in literature. key words

Multiple malignant

melanoma

Burn scar

Hyperpigmented lesion

1. Cirurgião oncológico; especialista em Cirurgia Oncológica pela Sociedade Brasileira de Cancerologia (SBC).

2. Médica patologista do Instituto de Anatomia Patológica; membro da Sociedade Brasileira de Patologia.

3. Médica; professora adjunta do Departamento de Medicina da Universidade Federal de São Carlos (UFSCar).

4. Médica patologista; professora assistente do Departamento de Medicina da UFSCar. 


\section{Introdução}

Estima-se que $2 \%$ dos pacientes com cicatrizes de queimaduras apresentem transformação neoplásica. A maioria dos casos se apresenta como carcinoma espinocelular, embora menos freqüentemente o carcinoma basocelular possa ser diagnosticado ${ }^{(1,10)}$. O surgimento de melanoma em cicatriz de antigas queimaduras é um evento extremamente raro ${ }^{(15)}$. Após revisão da literatura, encontramos a descrição de 29 casos, sendo que apenas quatro casos com mais de uma lesão foram relatados. Em virtude da raridade do diagnóstico e para familiarizar o patologista com as neoplasias que podem se desenvolver em regiões de cicatriz de queimadura, descrevemos neste artigo o caso de uma paciente de ascendência oriental com múltiplos melanomas em cicatriz de queimadura.

\section{Relato do caso}

Paciente do sexo feminino, 58 anos de idade, professora, descendente de japoneses, sofreu queimadura extensa por fogo, no tronco, aos 3 anos de idade. À época foi tratada sem enxertia de pele, sendo a ferida cicatrizada por segunda intenção, o que resultou numa extensa cicatriz de $13 \times 12 \mathrm{~cm}$ na região inframamária do hemitórax esquerdo. Há vários anos apresentava pigmentação extensa, estável, sobre a cicatriz. Como as lesões pigmentadas começaram a aumentar rapidamente no último ano, foram feitas duas biópsias excisionais em fuso: a maior media 2,1 $\times 1,2 \times$ $0,2 \mathrm{~cm}$ e a menor, $1,7 \times 0,8 \times 0,2 \mathrm{~cm}$. Esta, ao exame microscópico, foi diagnosticada como melanoma maligno superficial, não-ulcerado, com fases de crescimento radial e vertical, Clark II, Breslow 0,8 mm com discreto infiltrado linfocítico intratumoral e moderado infiltrado peritumoral, ausência de mitoses, ausência de regressão e de sateliose e margens cirúrgicas livres de neoplasia (Figura 1). A outra lesão era caracterizada por acantose com prolongamento das cristas interpapilares, intensa pigmentação da camada basal, discreto infiltrado inflamatório mononuclear perivascular e foi diagnosticada como lentigo simples. Uma terceira lesão foi ainda biopsiada com punch, medindo o cilindro $0,4 \times 0,6 \mathrm{~cm}$ de espessura. Ao exame microscópico foi diagnosticada como proliferação melanocítica atípica, sugerindo-se exérese para melhor avaliação.

Após o resultado da biópsia das lesões, o exame dermatoscópico detalhado de toda a área queimada mostrou algumas lesões com rede pigmentar de padrão irregular e com terminação abrupta na periferia. Outras lesões apresentavam glóbulos pigmentados com variação de cor (preto, castanho ou azulado). Essas lesões foram consideradas suspeitas para melanoma.

A paciente foi submetida a uma excisão ampla da área de cicatriz da queimadura, com margem cirúrgica de 1 $\mathrm{cm}$ e enxertia de pele da coxa. No exame macroscópico o retalho tinha forma irregular, medindo $13 \times 12 \times 1,5$ $\mathrm{cm}$. Com o auxílio de uma lupa, foram identificadas 12 lesões pigmentadas (Figura 2). Cada uma das lesões foi designada por uma letra e submetida à amostragem seriada. O exame histológico confirmou a presença de lesões melanocíticas, não-ulceradas, das quais sete corresponderam a melanomas de crescimento extensivo superficial. Estas apresentavam proliferação de células grandes, com grânulos de melanina, pleomorfismo celular, hipercromasia nuclear com núcleos de tamanho aumentado, alguns nucléolos eosinofílicos proeminentes e focos de migração intraepitelial pagetóide.

Em quatro desses melanomas, a infiltração de células anaplásicas, isoladas ou agrupadas, restringiu-se à epiderme (nível I de Clark - melanoma in situ) (Figura 3). Nos outros três, a infiltração estendeu-se até a derme papilar (nível Il de Clark) (Figura 4). A espessura máxima de infiltração encontrada foi de $0,37 \mathrm{~mm}$ (Breslow). Não foram

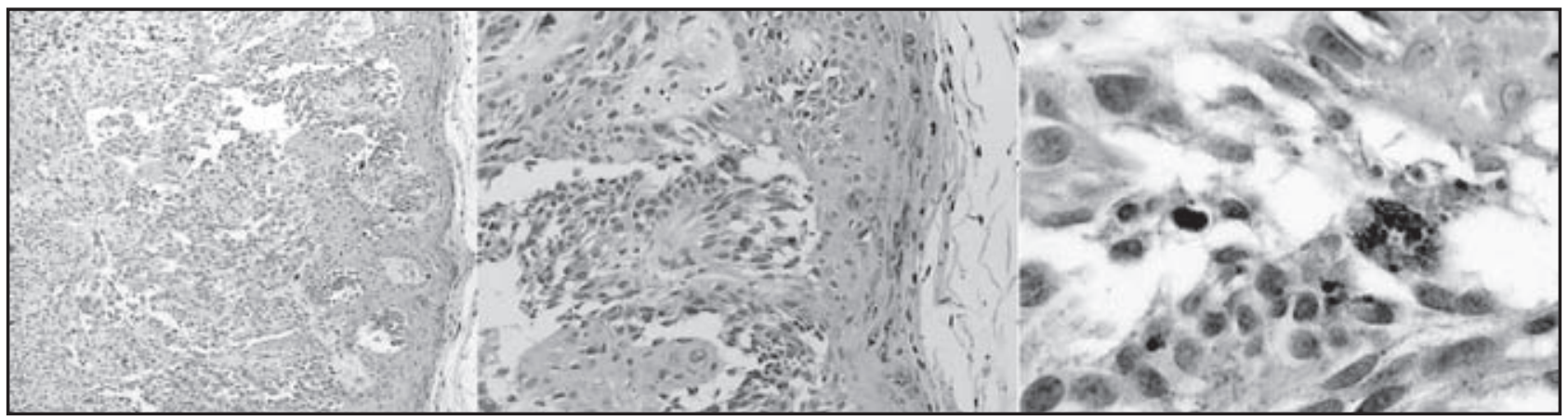

Figura 1 - Melanoma maligno: biópsia excisional (HE 40x, 100x e 400x) 


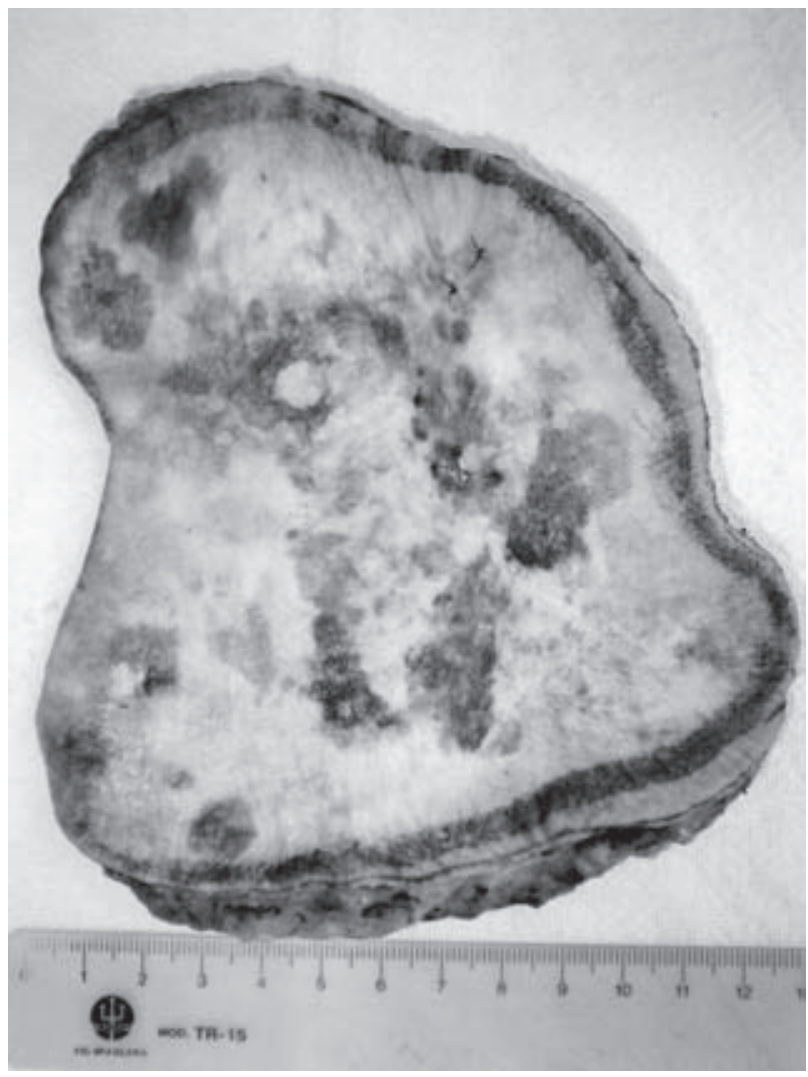

Figura 2 - Retalho de pele apresentando múltiplas lesões melanocíticas em área de cicatriz de queixo identificadas invasões angiolinfática e perineural, e o índice mitótico foi igual a 0 . A avaliação de sinais de regressão foi prejudicada pela fibrose cicatricial dérmica prévia, decorrente da queimadura. As margens cirúrgicas de ressecção do retalho estavam livres de neoplasia.

No material designado como linfonodo sentinela, foram dissecados três linfonodos de aspecto reacional, livres de metástases histológicas. As outras cinco lesões do retalho de pele foram diagnosticadas como hiperplasia melanocítica com graus variados de atipia.

A paciente encontra-se bem clinicamente, em acompanhamento médico regular há seis meses, sem sinal de recidiva das lesões ou de metástases regionais ou à distância.

\section{Discussão}

A presença de tumores em cicatrizes de queimadura não é incomum, entretanto o aparecimento de melanoma nessas áreas é muito raro ${ }^{(15)}$.

O primeiro caso de melanoma em cicatriz de queimadura foi descrito por Delacretaz et al. em 1970(4). Com a

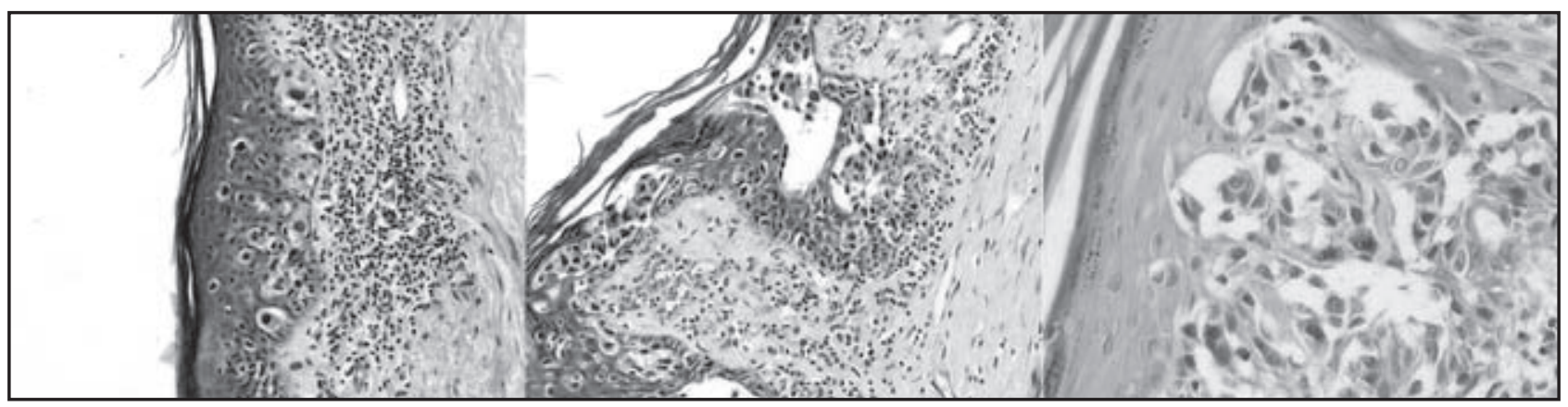

Figura 3 - Melanoma in situ, três lesões distintas (HE)

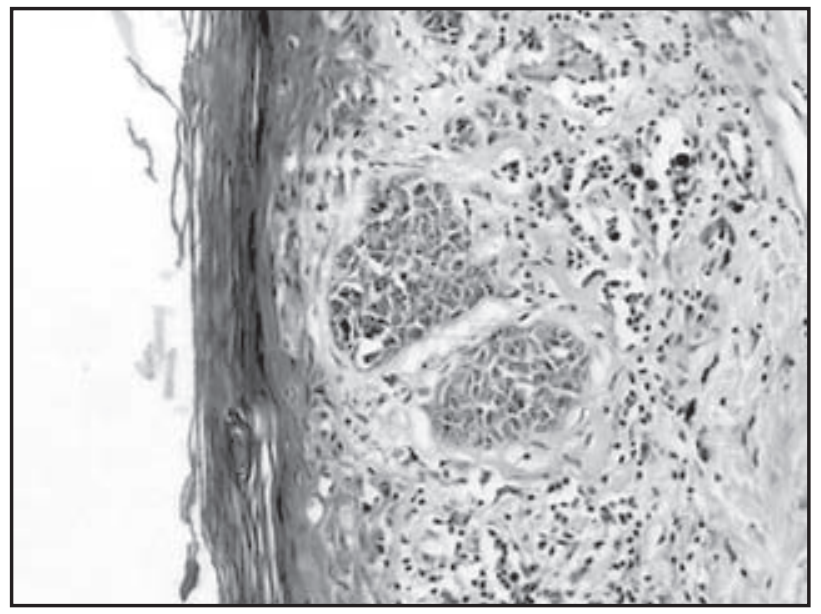

Figura 4 - Melanoma maligno nível Il de Clark (HE) inclusão do caso atual há, até o momento, cinco casos de múltiplos melanomas em cicatrizes de queimadura já descritos na literatura. O caso relatado nesse artigo é o primeiro descrito em publicação nacional e o único com mais de cinco lesões encontradas simultaneamente numa mesma área queimada, demonstrando a multifocalidade das lesões neoplásicas (Tabela).

Walker e Walker ${ }^{(17)}$ relataram o caso de uma paciente de 78 anos de idade, branca, que apresentava duas lesões distintas em área queimada. Ambas as lesões foram identificadas como melanoma, com extensão de 0,6 mm e 2 mm, localizadas no membro inferior. A paciente foi submetida à excisão ampla com enxerto de pele. 


\section{Resumo dos casos de melanomas múltiplos descritos em local de queimadura prévia}

Tabela

\begin{tabular}{|c|c|c|c|c|c|c|c|c|c|}
\hline Referência & Sexo & Origem & Idade & $\begin{array}{l}\text { Sítio } \\
\text { anatômico }\end{array}$ & Breslow & $\begin{array}{l}\mathrm{N}^{0} \text { de } \\
\text { lesões }\end{array}$ & $\begin{array}{l}\text { Tempo } \\
\text { médio de } \\
\text { surgimento } \\
\text { da } \\
\text { neoplasia }\end{array}$ & Linfonodo & $\begin{array}{l}\text { Seguimento/ } \\
\text { status }\end{array}$ \\
\hline \multicolumn{10}{|l|}{ Walker e } \\
\hline $\begin{array}{l}\text { Walker } \\
\text { (1989) }\end{array}$ & $\mathrm{F}$ & Caucasiana & 78 & extremidade & $\leq 2 \mathrm{~mm}$ & 2 & 67 anos & Não-relatado & 30 meses/SED \\
\hline $\begin{array}{l}\text { Ikeda et } \\
\text { al. (1995) }\end{array}$ & M & Oriental & 47 & extremidade & $\leq 2,5 \mathrm{~mm}$ & 2 & 37 anos & $\begin{array}{c}\mathrm{N}+ \\
\text { (esvaziamento } \\
\text { axilar) }\end{array}$ & 16 meses/AST \\
\hline $\begin{array}{l}\text { Hwang et } \\
\text { al. (2004) }\end{array}$ & M & Oriental & 58 & $\begin{array}{l}\text { tronco, } \\
\text { extremidade }\end{array}$ & $\leq 6 \mathrm{~mm}$ & 2 & 45 anos & Não-relatado & Desconhecido \\
\hline $\begin{array}{l}\text { Bero et al. } \\
\text { (2006) }\end{array}$ & $F$ & Caucasiana & 57 & tronco & $\leq 2,2 \mathrm{~mm}$ & 5 & 50 anos & $\begin{array}{c}\mathrm{N} \text { - } \\
\text { (esvaziamento } \\
\text { axilar e nódulo } \\
\text { sentinela) }\end{array}$ & 2 anos/SED \\
\hline $\begin{array}{l}\text { Relato de } \\
\text { caso atual } \\
\text { (2008) }\end{array}$ & $\mathrm{F}$ & Oriental & 58 & tronco & $\leq 0,8 \mathrm{~mm}$ & 8 & 55 anos & $\begin{array}{l}\text { N- (nódulo } \\
\text { sentinela) }\end{array}$ & 6 meses/SED \\
\hline
\end{tabular}

MIS: melanoma in situ; N-: ausência de metástases nos lifonodos pesquisados; SED: sem evidências da doença; AST: assintomática, em tratamento.

Ikeda et al. ${ }^{(8)}$ descreveram o caso de um paciente japonês de 41 anos de idade, com queimadura na região do cotovelo aos 4 anos, que apresentava duas lesões na cicatriz da queimadura. Uma delas foi diagnosticada como melanoma superficial com 2,5 mm de extensão, e a outra foi identificada como melanoma in situ. O paciente foi submetido a ressecção ampla e linfadenectomia axilar, tendo sido identificadas micrometástases em um linfonodo.

Hwang et al. ${ }^{(7)}$ descreveram o caso de um homem de origem coreana, 58 anos de idade, que sofreu uma queimadura em flanco e braço direitos aos 13 anos, com lesão característica de lentigo maligno melanoma invasivo no flanco, medindo $7 \times 6 \mathrm{~cm}$ de extensão e outra lesão no braço direito com $2 \times 2,5 \mathrm{~cm}$, diagnosticada como lentigo maligno melanoma, com invasão focal da derme reticular. O paciente foi submetido a ressecção ampla das lesões e enxerto de pele.

Bero et al. ${ }^{(2)}$ relataram o caso de uma mulher de origem paquistanesa, 57 anos de idade, que sofreu queimadura aos 5 anos, resultando em extensa cicatriz no tronco. Após 45 anos, a paciente apresentou lesão pigmentada na área da cicatriz. A lesão foi retirada e o diagnóstico foi de melanoma nodular, com 2,2 mm de extensão. A paciente foi submetida a ressecção da lesão com margem cirúrgica de $2 \mathrm{~cm}$ e dissecção de linfonodo sentinela, que se revelou livre de metástases. Após sete anos de seguimento, apresentou duas novas lesões na área da cicatriz, diagnosticadas como melanoma in situ. No oitavo ano de seguimento, surgiu nova lesão na mesma área, também identificada como melanoma in situ. Em 2005, houve o surgimento de outra lesão, também com resultado histopatológico de melanoma in situ.

Em nossa paciente encontramos ao todo oito melanomas distintos e simultâneos, sendo quatro melanomas invasivos e quatro melanomas in situ. Além dessas lesões havia outras cinco descritas como hiperplasia melanocítica atípica e um lentigo simples. As lesões foram diagnosticadas 55 anos após a queimadura. A paciente foi submetida à ressecção da área afetada com margem cirúrgica de $1 \mathrm{~cm}$. Realizou-se dissecção de linfonodo sentinela, que se revelou livre de metástases histológicas.

A patogênese do desenvolvimento de neoplasias em áreas de cicatriz por queimadura é desconhecida. Talvez a etiologia do desenvolvimento de carcinomas e melanomas seja a mesma. Alguns autores postulam 
que uma toxina carcinogênica é produzida no local da queimadura(12); outros, que a cicatriz de queimadura constitui ambiente favorável a alterações neoplásicas na presença de carcinógenos ambientais ${ }^{(5)}$. Por outro lado, a queimadura causa fibrose intensa, que oblitera vasos sangüíneos e linfáticos, levando à diminuição do aporte de nutrientes e de oxigenação da área, o que pode causar uma deficiência imunológica regional capaz de permitir o crescimento da neoplasia ${ }^{(16)}$. A fibrose da cicatriz pósqueimadura parece ser responsável, em parte, pelo longo período de tempo entre a ocorrência da queimadura e o surgimento das neoplasias ${ }^{(6)}$. Kikuchi et al. ${ }^{(9)}$ descreveram um tempo médio de 42 anos desde a queimadura até o desenvolvimento da neoplasia.

É interessante notar que em todos os casos de melanomas múltiplos descritos os pacientes queimados não foram submetidos a enxerto de pele e a cicatrização se deu por segunda intenção. Talvez a enxertia precoce dessas áreas queimadas pudesse prevenir o aparecimento de tais tumores.
Quanto às particularidades do melanoma que surgem na cicatriz de queimadura, é interessante ressaltar que o diagnóstico clínico de melanoma nessas lesões pode ser prejudicado pela presença de hiperpigmentação pósinflamatória na cicatriz ${ }^{(13)}$. É preciso também observar que dos cinco casos de múltiplos melanomas descritos, apenas num paciente foi encontrada metástase linfonodal. Também deve ser apontado que, de todos os 30 casos de melanoma em cicatriz de queimadura, foram descritos seis pacientes de origem japonesa, cuja etnia é considerada de baixo risco para melanoma cutâneo. Portanto, áreas suspeitas de pigmentação em cicatriz de queimadura devem ser biopsiadas, mesmo naqueles pacientes com pele escura ou nos oriundos de populações consideradas tradicionalmente de baixo risco para essa neoplasia.

O tratamento do melanoma em cicatriz de queimadura deve seguir as recomendações preconizadas para o melanoma cutâneo $(3,11,14)$ até que dados relevantes quanto às particularidades prognósticas desse tipo particular de neoplasia possam surgir.

\section{Referências}

1. ALCONCHEL, M. D.; OLIVARES, C.; ALVAREZ, R. Squamous cell carcinoma, malignant melanoma and malignant fibrous histiocytoma arising in burn scars. $\mathrm{Br} J$ Dermatol, v. 137, p. 793-8, 1997.

2. BERO, S. M.; BUSAM, K. J.; BRADY, M. S. Cutaneous melanoma arising in a burn scar: two recent cases and a review of the literature. Melanoma Res, v. 16, p. 71-6, 2007.

3. BLAZER, D. G.; SONDAK, V. K.; SABEL, M. S. Surgical therapy of cutaneous melanoma. Semin Oncol, v. 34 p. 270-80, 2007.

4. DELACrÉTAZ, J.; MEVORAH, B.; PeTtAVEL, J. Malignant melanoma appearing as the immediate sequel to a burn. Bull Soc Fr Dermatol Syphiligr, v. 77, p. 334-5, 1970.

5. GIBLIN, T. et al. Malignant degeneration in burn scars: Marjolin's ulcer. Ann Surg, v. 162, p. 291-7, 1965

6. GOLDBERG, N.S.; ROBINSON J.K.; PETERSON C. Gigantic malignant melanoma in a thermal burn scar. J Am Acad Dermatol, v. 12, p. 949-52, 1985.

7. HWANG, K.; HAN, J. Y.; LEE, S. I. Multiple malignant melanomas at different burn scar areas: a case report. Dermatol Surg, v. 30, p. 562-5, 2004.

8. IKEDA, I.; KAGESHITA, T.; ONO, T. Multiple malignant melanoma and squamous-cell carcinoma in a burn scar. Dermatology, v. 191, p. 328-32, 1995.

9. KIKUCHI, H. et al. Three cases of malignant melanoma arising on burn scars. J Dermatol, v. 30, p. 617-24, 2003.

10. MUHLEMANN, M. F.; GRIFFITHS, R. W.; BRIGGS, J. C. Malignant melanoma and squamous cell carcinoma in a burn scar. Br J Plast Surg, v. 35, p. 474-7, 1982.

11. NATIONAL COMPREHENSIVE CANCER NETWORK. Melanoma. NCCN Clinical Practice Guidelines in Oncology, v. 2, p. 1-35, 2007. 
12. OZEK, C. et al. Marjolin's ulcers arising in burn scars. J Burn Care Rehabil, v. 22, p. 384-9, 2001.

13. RICHTIG, E. et al. Repigmentation after surgery of melanoma in a burn scar: dermoscopy as aid for the management decision. Dermatol Surg, v. 33, p. 83941, 2007.

14. SAIAG, P. et al. Management of adult patients with cutaneous melanoma without distant metastasis. Eur J Dermatol, v. 17, p. 325-31, 2007.
15. SPRING, P.M. et al. Malignant melanoma arising within a burn scar: case report and review of the literature. Ann Otol Rhinol Laryngol, v. 110, p. 369-76, 2001.

16. TREVES, N. P. G. The development of cancer in burn scars: an analysis and report of thirty-four cases. Surg Gynecol Obstet, v. 51, p. 749-82, 1930.

17. WALKER, A. N.; WALKER, G. K. Scar-associated malignant melanoma and squamous carcinoma in situ. South Med J, v. 82, p. 1419-21, 1989. 